\title{
Bitter Gourd (Momordica charantia) Extract Activates Peroxisome Proliferator-Activated Receptors and Upregulates the Expression of the Acyl CoA Oxidase Gene in H4IIEC3 Hepatoma Cells
}

\author{
Che-Yi Chao Ching-jang Huang \\ Laboratory of Nutritional Biochemistry, Department of Biochemical Science and Technology and \\ Institute of Microbiology and Biochemistry, National Taiwan University, Taipei, Taiwan, ROC
}

\author{
KeyWords \\ Peroxisome proliferator-activated receptor $\alpha \cdot$ Stable \\ transfection - Bitter gourd · Hypolipidemic
}

\begin{abstract}
Peroxisome proliferator-activated receptor $\alpha$ (PPAR $\alpha$ ) is a ligand-dependent transcription factor that regulates the expression of genes involved in lipid metabolism and transport. Ligands/activators of PPAR $\alpha$, like fibrate-type drugs, may have hypolipidemic effects. To identify food that contains activators of PPAR $\alpha$, a transactivation assay employing a clone of CHO-K1 cells stably transfected with a (UAS) $)_{4}$-tk-alkaline phosphatase reporter and a chimeric receptor of Gal4-rPPAR $\alpha$ LBD was used to screen ethyl acetate (EA) extracts of a large variety of food materials. It was found that the EA extract of bitter gourd (Momordica charantia), a common oriental vegetable, activated PPARa to an extent that was equivalent to or even higher than $10 \mu M W y-14643$, a known ligand of PPAR $\alpha$. This extract also activated PPAR $\gamma$ to a significant extent which was comparable to $0.5 \mu M B R L-49653$. The activity toward PPAR $\alpha$ was mainly in the soluble fraction of the organic solvent. The EA extract prepared from the whole fruit showed significantly higher activity than that from seeds or flesh alone. The bitter gourd EA
\end{abstract}

extract was then incorporated into the medium for treatment of a peroxisome proliferator-responsive murine hepatoma cell line, H4IIEC3, for $72 \mathrm{~h}$. Treated cells showed significantly higher activity of acyl CoA oxidase and higher expressions of mRNA of this enzyme and fatty acid-binding protein, indicating that the bitter gourd EA extract was able to act on a natural PPARa signaling pathway in this cell line. It is thus worth further investigating the PPAR-associated health benefits of bitter gourd.

Copyright 12003 National Science Council, ROC and S. Karger AG, Basel

\section{Introduction}

Peroxisome proliferator-activated receptors (PPARs) are lipid-activated transcription factors that control energy homeostasis through genomic action [41]. As other members of the steroid hormone nuclear receptor superfamily do, PPARs have a common modular structure including a DNA-binding domain and a ligand-binding domain (LBD) [9, 36]. Upon activation by a ligand, PPAR heterodimerizes with the RXR and promotes transcription of its target genes through binding to a peroxisome proliferator-responsive element (PPRE) [9, 41]. Three subtypes of this receptor exist, namely PPAR $\alpha$

\section{KARGER}

$\mathrm{Fax}+41613061234$ E-Mail karger@karger.ch www.karget.com
(C) 2003 National Science Council, ROC

$S$. Karger $A G$, Basel

1021 - 7770/03/0106-0782\$19.50/0

Accessible online at:

www. karger.com/jos
Ching-jang Huang, $\mathrm{PhD}$

Department of Biochemical Science and Technology

National Tawan University, 1 Roosevelt Road, Sec. 4

Taipei 106, Taiwan (ROC)

Tel.Fax +886223621301 , E-Mail cjhuang@ntu,edu,tw 
(NR1C1), PPAR $\beta / \delta$ (NR1C2) and PPAR $\gamma$ (NR1C3), which display tissue-selective expression patterns and distinct biological functions. PPAR $\alpha$ is predominantly expressed in the liver, heart, kidney, and skeletal muscle where it controls fatty acid catabolism. PPAR $\gamma$ is highly expressed in brown and white adipose tissue where it triggers cellular differentiation, promotes lipid storage, and modulates the action of insulin. PPAR $\beta / \delta$ is ubiquitously expressed and controls brain lipid metabolism and fatty acid-induced adipogenesis and preadipocyte proliferation $[9,41]$. Recent reports have further demonstrated a role of PPAR in regulating glucose homeostasis, cellular differentiation and apoptosis, and cancer development as well as in controlling the inflammatory response [7, 19].

Being the ligand/activator of PPARa, fibrate-type hypolipidemic drugs can induce the expression of genes that participate in aspects of lipid catabolism such as fatty acid uptake and binding, fatty acid oxidation (in microsomes, peroxisomes, and mitochondria), and lipoprotein assembly and transport [36]. These are PPAR $\alpha$ target genes since PPRE has been identified in the promoter region of these genes. Using a PPAR $\alpha$-deficient mouse model, the hypolipidemic action of fibrates was found to be mediated by this receptor [31]. The results indicated that the PPAR $\alpha$ ligand/activator may lower liver and/or blood lipids by upregulating PPAR $\alpha$ target genes, which in turn enhance the oxidation of fatty acids [36]. Likewise, thiazolidinediones are PPAR $\gamma$ ligands, and the antidiabetic effects of this type of drug are believed to be mediated by PPAR $\gamma[3,43]$. Substantial attempts are currently being made to develop new therapeutic agents for hyperlipidemia, insulin resistance, or atherosclerosis by screening agonists/antagonists of PPARs [33, 41]. Attention has especially been paid to compounds that serve as ligands for both the $\alpha$ - and $\gamma$-subtypes of PPAR [33, 41]. A similar approach was thus employed in this study for the purpose of identifying PPAR $\alpha$ activators from food materials.

PPAR activators of food/diet origin may provide health benefits without toxicity concerns, as long as the food/diet is consumed in a reasonable amount on a regular basis. A number of PPAR activators that are of food/ diet origin have been identified. Conjugated linoleic acids (CLA) [29] and phytanic acid $[11,12]$ are well-known examples. Although the mechanism of action is not fully understood, CLA [4] has health benefits such as antiatherogenic, antidiabetic, and anticarcinogenic effects, while phytanic acid induces brown adipocyte differentiation and UCP-1 transcription [35]. The hypolipidemic effect of fish oil [8] has been attributed, at least in part, to the activation of PPAR $\alpha$. Oxidized lipids in oxidized frying oil can activate PPAR $\alpha$, upregulate some PPAR $\alpha$ target genes, and reduce plasma and liver triglycerides in rats [5].

In this study, we screened a large number and variety of food materials, and found that bitter gourd (Momordica charantia) contains PPAR $\alpha$ and $\gamma$ activator(s) that can be extracted by an organic solvent. The activating effect on natural PPAR $\alpha$ was further demonstrated in H4IIEC3, a peroxisome proliferator-responsive murine hepatoma cell line.

\section{Materials and Methods}

\section{Expression and Reporter Vectors}

The chimeric receptor constructs used were pBK-CMV-Gal4rPPAR $a$-ligand-binding domain (Gal4-rPPARaLBD) and the pBKCMV-Gal4-rPPAR $\gamma$-ligand-binding domain (Gal4-rPPAR $\gamma \mathrm{LBD}$ ), respectively. The reporter gene was pBK-CMV-(UAS) $)_{4}$ tk-alkaline phosphatase (AP), and the antibiotic genes were $\mathrm{pSV}_{2}$-neomycin and pKSV-hygromycin. These were gifts from Dr. J.A. Gustaffson, Department of Medical Nutrition, Karolinska Institute, Huddinge, Sweden. The correct in-frame fusions were confirmed by sequencing.

\section{Cell Culture and Stable Transfection}

Procedures for the establishment of cell lines stably transfected with the Gal4-rPPAR $\alpha$ LBD chimeric receptor and (UAS) ${ }_{4}$-tk-AP reporter have been described previously [15]. Briefly, CHO-K1 cells (American Type Culture Collection, Rockville, Md., USA) were grown at $37^{\circ} \mathrm{C}$ in the presence of $5 \% \mathrm{CO}_{2}$ in Ham's $\mathrm{F}-12$ medium supplemented with $10 \%$ fetal bovine serum (Gibco BRL, Rockville, Md., USA). Using Lipofectamine ${ }^{\mathrm{TM}} 2000$ (Gibco BRL) according to the manufacturer's instructions, cells were first transfected with the reporter construct and $\mathrm{pSV}_{2}-\mathrm{Neo}$. Transfected cells were selected in the presence of $0.8 \mathrm{mg} / \mathrm{ml}$ medium of $\mathrm{G} 418$ (neomycin). The colonies grown were pooled to form a reporter clone mix and further transfected with the chimeric receptor construct $\mathrm{pBK}-\mathrm{CMV}-\mathrm{Gal4}-\mathrm{PPPA}$ $\mathrm{R} \alpha$ and $\mathrm{pKSV}$-Hygro, and then selected with $0.8 \mathrm{mg} / \mathrm{ml}$ medium of hygromycin. About 160 clones were picked, expanded, and tested for their responsiveness to $50 \mu \mathrm{mol} / \mathrm{W} \mathrm{W}-14643$ (Cayman Chemicals, Ann Arbor, Mich., USA), a known activator of PPARa. Among the 10 responsive clones, clone 77 showed the maximal induction of reporter gene AP activity, and was used for the following experiments. The expression of PPAR $\alpha$-LBD in cells of clone 77 was confirmed by RT-PCR.

\section{Food Extracts for Testing}

Tested food materials were chosen from vegetables, fruits, nuts, traditional Chinese herbs, and microbial products. Fresh vegetables included bitter gourd ( $M$. charantia L), onion, celery, sweet potato leaves, and rice seedlings; fruits included lychee (litchi or Litchi sinensis Sonn) and longan (Nephelium longana Camb or Euphoria longana Lam); nuts included freshly roasted peanuts and sesame seeds; dried traditional Chinese herbs included ricinus seed (Ricini semen), lotus seed plumule (Nelumbo nucifera Gaertn), and hawthorn (Crataegi fructus), and microbial products included Monascus 
anka (dried powder of Chinese red yeast rice), Ganoderma tsugae, lactic acid bacteria, and desalted pressed residue of soy sauce mash.

Tested food materials were extracted as previously described [16, 44], but only the ethyl acetate (EA) extract was used for testing in this study. This is because ligands of PPARs are known to be relatively hydrophobic. Briefly, samples were homogenized in a Waring blender with a minimal amount of double-distilled water, and homogenates were filtered through several layers of gauze. The residues were collected, freeze-dried, ground up, and extracted with EA (1:30, w/v) by stirring overnight at room temperature. The EA solutions were filtered, and the filtrates were evaporated in a rotary evaporator (Buchi, Essen, Germany) to remove the solvent. The ethyl acetate extracts (EAEs) were weighed and stored at $-20^{\circ} \mathrm{C}$.

\section{Transactivation Experiments and Reporter Gene Assay}

For the transactivation experiments, the EAEs of tested samples were dissolved in a minimal amount of ethanol or dimethyl sulfoxide (DMSO). They were then diluted to appropriate concentrations with Ham's F-12 medium containing 10\% serum replacement (TCM, Celox, St. Paul, Minn., USA) immediately before use.

The procedure of the transactivation assay has previously been described [5]. Briefly, stably transfected cells were seeded in 96-well plates and incubated with medium containing Wy-14643 and the tested food extracts or vehicles (DMSO or ethanol) for $48 \mathrm{~h}$. Culture medium was then collected and assayed for $\mathrm{AP}$ activity using CSPD ${ }^{\circledR}$ (Tropix, Applied Biosystems, Foster City, Calif., USA) as the substrate and Sapphire-II as the enhancer. Chemiluminescence was measured in a luminometer (Wallac 1420 Victor $^{2}$ multiple label counter; Perkin Elmer, Turku, Finland). The viability of treated cells was checked by the MTT (Sigma, St. Louis, Mo., USA) assay. Data reported are confined to those for which treatment did not significantly change the cell viability. Folds of activation were calculated by taking the AP activity of vehicle-treated cells as 1 .

\section{Distribution of the PPARa Activator in Bitter Gourd}

To examine the distribution of the PPAR $a$ activator in different parts of bitter gourd, the flesh, seeds, and whole fruit of green bitter gourd were, respectively, extracted and compared for their PPAR $\alpha$ activation ability using the transactivation assay described above. To compare the activity of four different varieties of bitter gourd, whole fruits of white, green, pearl-shaped, and wild bitter gourd (fig. 2b) were extracted as described above and tested using the transactivation assay.

\section{Extraction of the PPAR $\alpha$ Activator of Bitter Gourd}

Green bitter gourd whole fruit was extracted by several procedures, and the extracts obtained were tested for their PPAR $\alpha$-activating potential using the transactivation assay described above. Fresh green bitter gourd whole-fruit samples were homogenized in a Waring blender with a minimal amount of double-distilled water, and homogenates were filtered through several layers of gauze. The juice was further centrifuged at $10,500 \mathrm{~g}$ at $4^{\circ} \mathrm{C}$ for $30 \mathrm{~min}$, and the precipitate was collected and added to the filtered residue. The clear supernatant of juice and the residue were freeze-dried. The dried residue was ground up and extracted with EA (1: 30, w/v) by stirring overnight at room temperature. The EA solutions were filtered, and the filtrates were evaporated in a rotary evaporator (Buchi) to remove the solvent. The EAEs were weighed and stored at $-20^{\circ} \mathrm{C}$. The yield of bitter gourd EA extract in this extraction procedure was $\sim 1.8 \mathrm{~g} / \mathrm{kg}$ fresh whole fruit. In a set of experiments, EA was replaced by n- hexane. Alternatively, sample material was sliced, freeze-dried, and directly extracted with $\mathrm{EA}$, and the EAE was partitioned using a saturated $\mathrm{NaCl}$ aqueous solution. On the other hand, sample material was directly extracted using methanol, and then the methanol extract was sequentially partitioned using n-hexane, EA, and n-butanol.

\section{Transient Transfections}

Cells transfected with the reporter construct (reporter clone mix obtained in the first stage of stable transfection as described above) were used in this experiment. Nearly confluent cells were seeded in 96-well plates and transfected with $0.2 \mu \mathrm{g}$ of the chimeric receptor construct $\mathrm{pBK}-\mathrm{CMV}$-Gal4-PPARa or pBK-CMV-Gal4-PPAR $y$ using $1.2 \mu \mathrm{l}$ of Lipofectamine 2000 reagent in $100 \mu \mathrm{l}$ serum-free medium OPTI-MEM ${ }^{\circledast}$ (Gibco BRL) per well. After $5 \mathrm{~h}$, the medium was changed to Ham's F-12 medium containing $10 \%$ serum replacement and vehicle (ethanol or DMSO), $10 \mu M$ Wy-14643, $0.5 \mu M$ BRL-49653 or appropriate concentrations of wild bitter gourd whole-fruit EA extract. Medium was collected $48 \mathrm{~h}$ later and analyzed for alkaline phosphatase activity as described above.

\section{Treatment of the H4IIEC3 Cell Line with Bitter Gourd EA \\ Extract}

H4IIEC3 cells (American Type Culture Collection) are Reuber rat hepatoma cells that offer a good in vitro model system of the induction of peroxisomes and peroxisomal $\beta$-oxidation enzymes by peroxisome proliferators. H4IIEC 3 cells were maintained at $37^{\circ} \mathrm{C}$ in the presence of $5 \% \mathrm{CO}_{2}$ in Dulbecco's modified Eagle's medium supplemented with $20 \%$ horse serum (Gibco) and $5 \%$ fetal bovine serum (Gibco). Near confluence, cells were seeded at a density of 60,000 cells $/ \mathrm{ml}$ into $10-\mathrm{cm}$ dishes and grown for $24 \mathrm{~h}$ in the same medium under $5 \% \mathrm{CO}_{2}$ at $37^{\circ} \mathrm{C}$. The EAE of the dried water-insoluble fraction of wild bitter gourd whole fruit was dissolved in a minimal amount of absolute ethanol and diluted with the medium to a concentration of 50,100 , or $150 \mu \mathrm{g} / \mathrm{ml}$, respectively, and used to treat these cells. Blank dishes received vehicle (medium containing 0.1 or $0.3 \%$ absolute ethanol) only. Cells treated with medium containing $50 \mu M \mathrm{Wy}-14643$ or $500 \mu M$ clofibrate served as positive controls. After $72 \mathrm{~h}$ of treatment, cells were harvested for analysis of acyl $\mathrm{CoA}$ oxidase (ACO) activity, and expressions of mRNA of ACO and fatty acid-binding protein (FABP).

\section{ACO Activity Assay and Northern Blot Analysis}

Harvested cell pellets were homogenized, and the postnuclear supernatant fraction was isolated and analyzed for ACO activity according to the method of Small et al. [38]. To determine the mRNA of ACO and FABP by Northem blot, total RNA was extracted from the harvested cell pellet using trizol reagent (Life Technologies, Rockville, Md., USA). Twenty micrograms of extracted RNA from each treated cell sample was separated by electrophoresis in denaturing formaldehyde agarose (1\%) gel, transferred to a nylon membrane (Gene Screen Plus; DuPont, Boston, Mass., USA), and cross-linked to the membrane by UV irradiation. The blots were prehybridized at $42^{\circ} \mathrm{C}$ for $3 \mathrm{~h}$ in the hybridization buffer excluding the probe but containing salmon sperm DNA. It was then hybridized at $42^{\circ} \mathrm{C}$ for $12-$ $16 \mathrm{~b}$ with ${ }^{32} \mathrm{P}-1$ labeled cDNA probes of $\mathrm{ACO}$ and FABP, respectively. To correct for possible differences in transfer and loading, blots were also hybridized with labeled $\beta$-actin probe as an internal control. Afterward, blots were washed at the appropriate stringency to remove nonspecific binding and were exposed to X-OMAT AR film (Kodak, Rochester, N.Y., USA). Signals were analyzed quantitative- 
ly using a microcomputer imaging device (MCID) image analysis system (Fuji, Tokyo, Japan). The ACO and $\beta$-actin cDNA probes used were previously described [5]. The FABP cDNA probe [bases: 33405; GenBank (NCBI) accession No. M35991] was synthesized by RT-PCR. Rat liver RNA was reverse-transcribed to cDNA and used as the template, and the primer sequences were 5'-TGCCACCATGAACTTCTCC-3' (forward) and 5'-TCTCTTGTAGACGATGTCACC-3' (reverse). All of the cDNA probes used were confirmed by sequence analysis.

\section{Data Analysis}

Data reported are expressed as the mean \pm standard deviation of triplicate wells, and are representative of at least three separate experiments with similar results. The significance of difference between each treatment was analyzed by one-way ANOVA using SAS $^{\circledR}$ (SAS 8.1, Cary, N.C., USA) software.

\section{Results}

\section{Cell Clones Obtained from Stable Transfection}

After successive transfection with the (UAS) ${ }_{4}$-AP reporter and Gal4-rPPAR $\alpha$ LBD chimeric receptor, about 160 clones of cells that grew in the presence of $0.8 \mathrm{mg} / \mathrm{ml}$ hygromycin were picked, expanded, and tested for their responsiveness to $\mathrm{Wy}-14643$, a known PPAR $\alpha$ ligand. Ten clones were found to be responsive and further expanded. Figure la shows the dose-dependent expression of the AP reporter gene of 1 of these clones, clone 77 , in response to $\mathrm{Wy}-14643$. This cell clone also responded to a number of known PPAR $a$ activators including common and oxidized fatty acids, CLA, and phytanic acid in a manner similar to the results reported in the literature (data not shown). Therefore, clone 77 was considered to be acceptable and was used in the later transactivation assay for estimating the PPAR $\alpha$-activating potential of various food extracts. Throughout batches of experiments in which different passages of clone 77 were used, the folds of activation of $10 \mu \mathrm{MWy}$ - 14643 ranged from 2 to 4. The folds of activation of $10 \mu M \mathrm{Wy}-14643$ were highest when a vial of an early passage of clone 77 cells was thawed, but the value decreased gradually as the passage number increased. Cells were discarded when the folds of activation of $10 \mu M \mathrm{Wy}-14643$ approached 2 .

The PPARa-Activating Ability of Tested Food Extracts Using cells of clone 77, the EAEs of food materials were tested for their transactivation of PPAR $\alpha$. Most of the tested samples showed low or moderate activity (data not shown). However, the extract of bitter gourd showed such a high activity that the maximum fold of activation was comparable to that of $10 \mu M$ of Wy-14643. The dosedependent activation of bitter gourd EA extract on PPA-

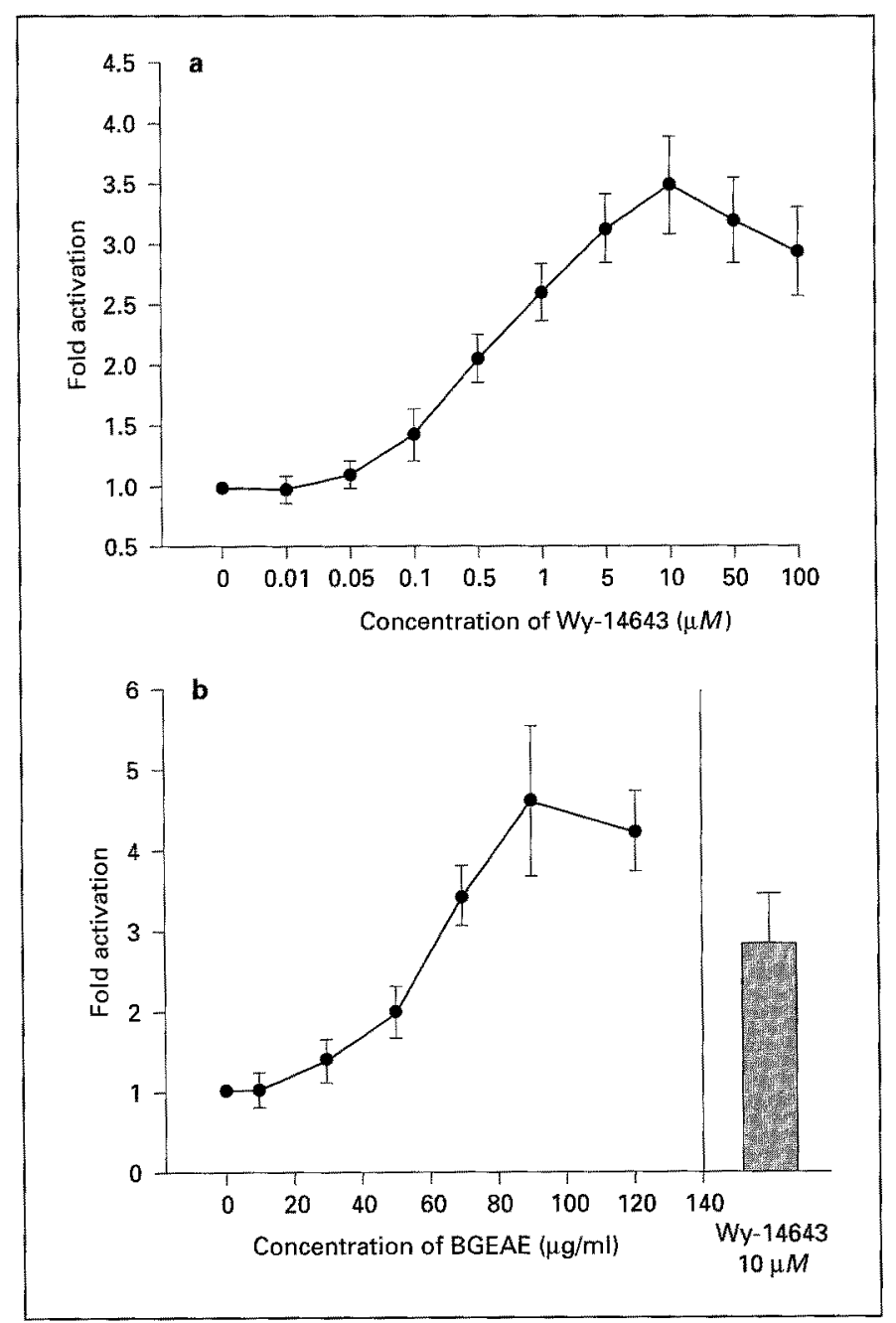

Fig. 1. Transactivation of Gal4-rPPAR $\alpha$ by $W y-14643$ and green bitter gourd EA extract. Dose-response curve of Wy-14643 (a) and bitter gourd EA extract (BGEAE) (b) in CHO-K1 cells stably transfected with the Gal4-rPPAR a receptor chimera and the AP reporter. CHO-K1 cells were successively transfected with the reporter and receptor construct. Folds of activation were calculated by taking the AP activity of the vehicle (ethanol)-treated cells as 1. Values are the mean $\pm \mathrm{SD}$ of triplicate wells from 1 experiment and are representative of 10 separate experiments. The $\mathrm{EC}_{50}$ of $\mathrm{Wy}-14643$ was $0.5 \mu \mathrm{M}$ and of BGEAE was $70 \mu \mathrm{g} / \mathrm{ml}$, respectively.

$\mathrm{R} \alpha$ is shown in figure $1 \mathrm{~b}$, and the $\mathrm{EC}_{50}$ was estimated to be $70 \mu \mathrm{g} / \mathrm{ml}$. The maximal fold of activation was attained by $90 \mu \mathrm{g} / \mathrm{ml}$ of green bitter gourd EA extract.

\section{Distribution of the PPAR $\alpha$ Activator in Bitter Gourd}

Although the EA extract prepared from seed or flesh significantly activated $\operatorname{PPAR} \alpha$, bitter gourd whole-fruit EA extract showed still higher activity $(p<0.05)$ than the seed or flesh extract (fig. 2a). At concentrations of 100 or 

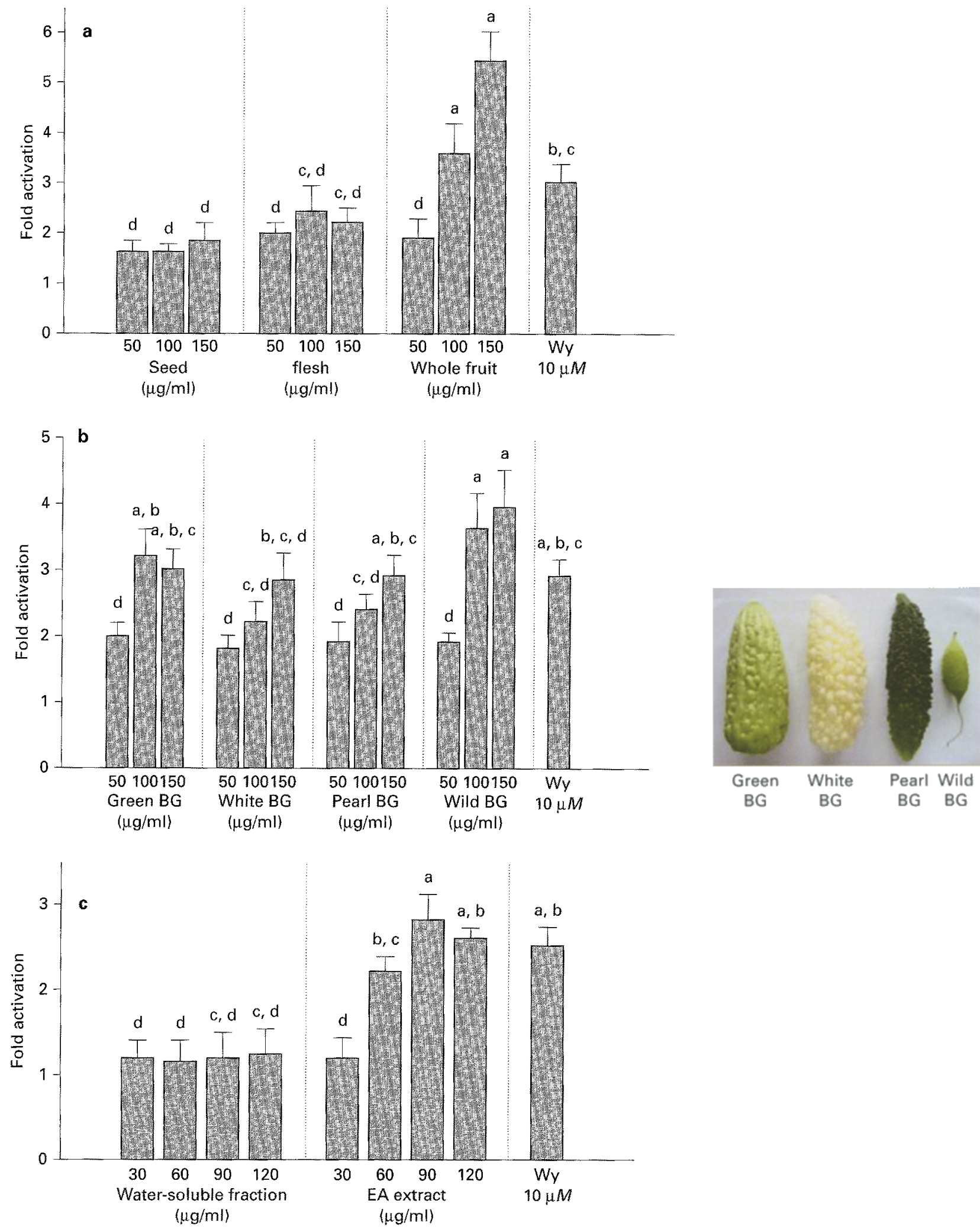


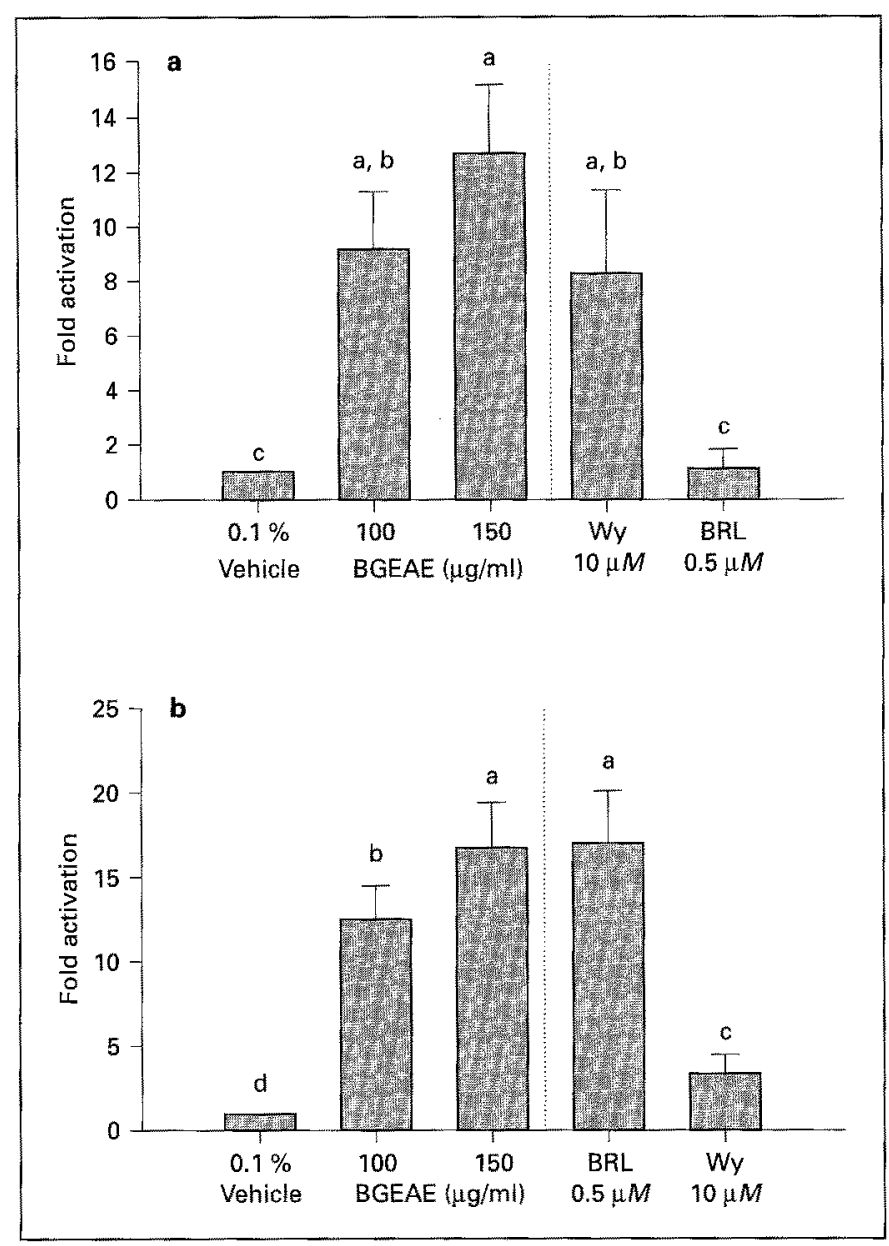

Fig. 3. Transactivation of Gal4-rPPAR $\alpha$ (a) and Gal4-rPPAR $\gamma(\mathbf{b})$ by wild bitter gourd EA extract (BGEAE) in transient transfection experiments. Folds of activation were calculated by taking the AP activity of the vehicle (ethanol) as 1 . Values are the mean $\pm \mathrm{SD}$ of triplicate wells from 1 experiment. Data shown are representative of 3 separate experiments with similar results. Wy-14643 $(10 \mu M)$ and BRL-49653 $(0.5 \mu M)$ were used as positive controls. Values not sharing the same letter significantly differ from one another by one-way ANOVA and Duncan's multiple range test $(p<0.05)$.

Fig. 2. Distribution of the PPAR $\alpha$ activator in bitter gourd (BG). CHO-K 1 cells stably transfected with the Gal4-rPPAR $\alpha$ receptor chimera and the AP reporter (clone 77) were used to determine the transactivation of PPAR $\alpha$ by EA extracts of seeds, flesh, or whole fruit of green bitter gourd (a), EA extract of 4 varieties of bitter gourd (b), and the green bitter gourd water-soluble fraction and EA extract of the water-insoluble fraction (c). Folds of activation were calculated by taking the AP activity of the vehicle (ethanol)-treated cells as 1. Values are the mean $\pm \mathrm{SD}$ of triplicate wells from 1 experiment. Data shown are representative of 3 separate experiments with similar results. $\mathrm{Wy}-14643(10 \mu M)$ was included as a positive control. Values not sharing the same letter significantly differ from one another by one-way ANOVA and Duncan's multiple range test $(p<0.05)$.
$150 \mu \mathrm{g} / \mathrm{ml}$, the EA extract of four varieties of bitter gourd all showed significant activation of PPAR $a$ that was comparable to that of $10 \mu M$ of $W y-14643$ (fig. 2b). But the EA extract of white bitter gourd had a significantly lower value for the maximal fold of activation $(p<0.05)$ compared to those of the remaining three varieties of bitter gourd.

\section{Extraction of the PPAR $\alpha$ Activator from Bitter Gourd}

As shown in figure $2 \mathrm{c}$, the water-soluble fraction of bitter gourd did not activate PPAR $\alpha$ at all, whereas the EA extract of the dried water-insoluble fraction showed significant activation which was comparable to $10 \mu M$ of $\mathrm{Wy}-14643$. The fold of activation of the $\mathrm{n}$-hexane extract of the dried water-insoluble fraction did not significantly differ from that of the EA extract.

Alternatively, green bitter gourd whole fruit was freezedried and directly extracted with EA, and the EAE was partitioned using a saturated $\mathrm{NaCl}$ aqueous solution. This salt solution-washed EA extract also activated PPAR $\alpha$ to an extent comparable to the EA extract from the original extraction procedure (residue from the water extraction subsequently extracted by EA). When bitter gourd was extracted with methanol and sequentially partitioned using n-hexane, EA, and n-butanol, only the n-hexane fraction activated PPAR $\alpha$ to an extent comparable to the EA extract obtained from the original procedure (data not shown). These results indicated that the PPAR $\alpha$ activator in bitter gourd is preferentially extracted by relatively nonpolar organic solvents, such as EA and n-hexane.

\section{Transient Transfection with the PPARa or PPAR Chimeric Receptor}

The transient transfection approach was also employed to test PPAR activation of the bitter gourd EA extract since the folds of activation observed in the transactivation assay using our stably transfected clone 77 cells were relatively low compared to data reported in the literature using transient transfection. The result with the PPAR $\alpha$ chimeric receptor was very similar to that of the transactivation assay using our stable cell clone 77 , but the fold of activation was higher and comparable to some reported data. Wild bitter gourd EA extract showed equivalent $(100 \mu \mathrm{g} / \mathrm{ml})$ or higher $(150 \mu \mathrm{g} / \mathrm{ml})$ activation of PPAR $\alpha$ compared to that of $10 \mu M$ Wy-14643 (fig. 3a). Excitingly, wild bitter gourd EA extract also significantly activated PPAR $\gamma$. As shown in figure $3 b$, the fold of activation of $150 \mu \mathrm{g} / \mathrm{ml}$ wild bitter gourd EA extract was equivalent to that of $0.5 \mu M$ BRL-49653, a well-known PPAR $\gamma$ ligand. 


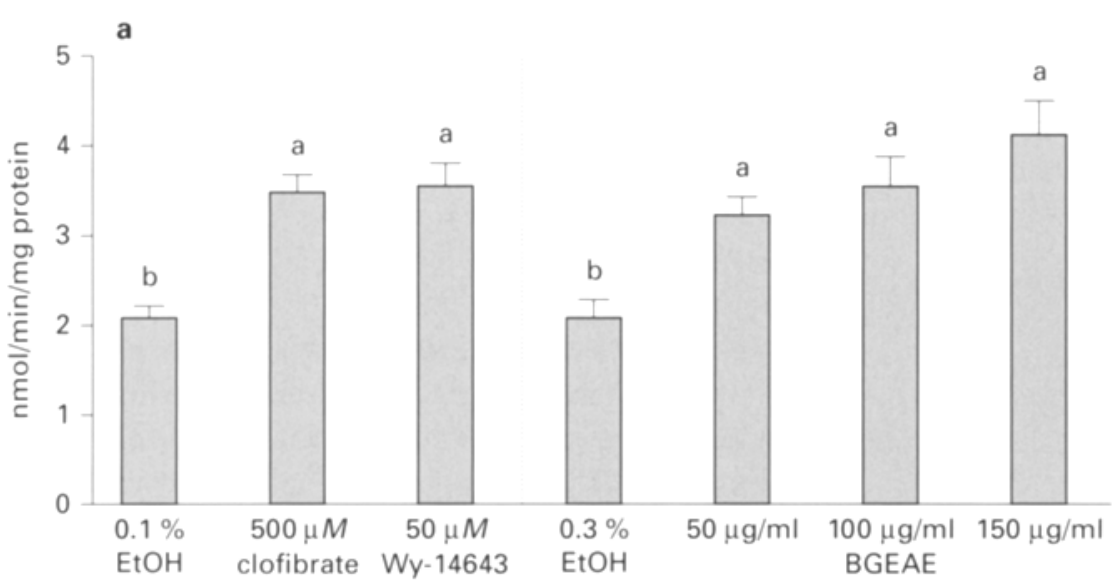

b

Wy Veh $\quad \begin{gathered}\text { BGEAE } \\ \quad 100 \quad 150\end{gathered}$

$\mathrm{ACO}$

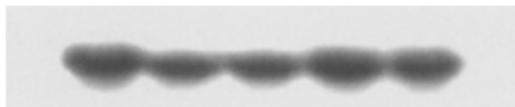

FABP

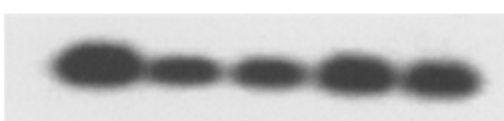

$\beta$-actin
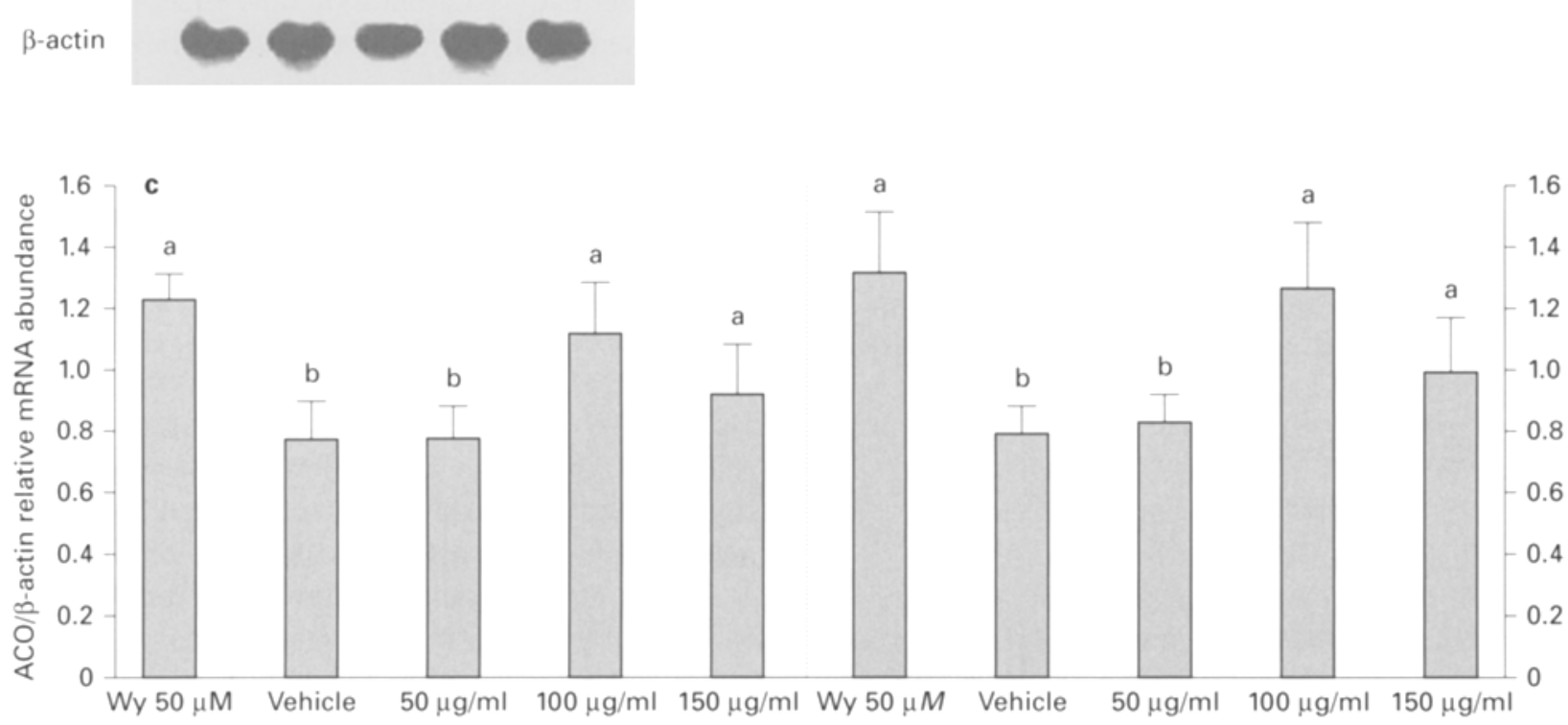

Fig. 4. a The ACO activity of $\mathrm{H} 4 \mathrm{IIEC} 3$ cells treated with clofibrate, Wy-14643 (Wy), or EA extract of wild bitter gourd (BGEAE) for $72 \mathrm{~h}$. b Northern blot analysis for mRNA of ACO and FABP in H4IIEC3 cells treated with Wy or BGEAE for $72 \mathrm{~h}$. WY: $50 \mu \mathrm{M}$; BGEAE: 50 , 100 or $150 \mu \mathrm{g} / \mathrm{ml}$. c Total RNA $(20 \mu \mathrm{g})$ isolated from treated cells was separated by electrophoresis, transferred to nylon membranes, and then hybridized with an ACO or FABP CDNA probe. Signals were quantitated by image analysis. Each value was normalized by $\beta$-actin (as the internal control). Values are the means \pm SD of triplicate experiments. Values not sharing the same letter are significantly different from one another by one-way ANOVA and Duncan's multiple range test $(\mathrm{p}<0.05)$. 


\section{H4IIEC3 Cells Treated with Bitter Gourd EAEs}

To test whether the bitter gourd EA extract can act on natural PPARa, H4IIEC3 cells were treated with this extract for $72 \mathrm{~h}$. The activity of ACO in treated cells was about 1.8 -fold $(\mathrm{p}<0.05)$ that of vehicle-treated cells, and did not significantly differ from that of cells treated with Wy-14643 or clofibrate (fig. 4a). The expression of mRNA of ACO and FABP in treated cells determined by Northern blot and image analysis is shown in figure $4 b, c$. Similar to cells treated with $50 \mu M$ Wy-14643, cells treated with 100 or $150 \mu \mathrm{g} / \mathrm{ml}$ of bitter gourd EA extract showed significantly higher mRNA expression of ACO and FABP than cells treated with vehicle only. The result indicated that bitter gourd EA extract could act on a natural PPAR $\alpha$ signaling pathway.

\section{Discussion}

Ligand binding of PPARs can induce the expression of an array of genes that in turn can change the metabolism of lipids and/or the utilization of glucose. A number of therapeutic agents, namely fibrate hypolipidemic drugs and thiazolidinedione antidiabetic drugs, are ligands of PPARs and the pharmacological effects were shown to be mediated by these nuclear receptors $[7,36,43]$. The transactivation assay is used to test the functional potency of a compound to activate PPAR. The assay measures the expression of a reporter gene that is driven by a promoter responsive to the specific binding of the transcription factor, PPAR. As PPARs are ligand-dependent transcription factors, molecules binding to PPARs activate expression of the reporter gene. To avoid complicating the interpretation of results by endogenous receptor activation, a chimeric receptor in which the PPAR $\alpha \mathrm{LBD}$ is fused to the yeast transcription factor GAL4 DNA-binding domain and a reporter construct containing four copies of the GAL4 DNA-binding site UAS which drives expression of secreted placental alkaline phosphatase were used in this study. The approach is similar to that used for screening compounds in pharmaceutical research and development [13]. Compared to the transient transfection approach, it is more convenient to use clones of cells stably expressing the transfected receptor and reporter for compound screening. However, it usually takes a longer time to obtain such a clone, and very often the clone may suffer from instability and loss of sensitivity due to passages of cells. In this study, this can be seen from variations in the folds of activation of the positive control, $\mathrm{Wy}$ 14643.

Bitter Gourd Activates PPAR
The EA, rather than the water, extract of food materials was chosen for testing in this study, since the ligandbinding structure of PPAR $\alpha$ was confirmed to prefer hydrophobic molecules. Among various food materials tested, bitter gourd was found to activate PPAR $\alpha$ to an extent comparable to Wy-14643. Bitter gourd is an important cultivated food crop in Asian countries and is recognized as being of medicinal value in Indian and Chinese traditional medicine. Indeed, the juice or whole powder of bitter gourd fruit has been reported to have various medicinal properties, including anticarcinogenic [22], hypoglycemic $[14,18,28,42]$, and hypotriglyceridemic [17] effects. These effects are closely related to the role of PPAR in regulating lipid and glucose homeostasis, cellular differentiation and apoptosis, and cancer development as well as in controlling the inflammatory response [7, 19]. Our transactivation assay further demonstrated that all four varieties of bitter gourd commonly seen in local Taiwanese markets produce high activation of PPAR $\alpha$. The activity is higher in whole fruit than in flesh or seeds and can be extracted by relatively nonpolar organic solvents, such as EA and n-hexane, as would be expected by the hydrophobic nature of the active compound.

$A C O$ and FABP are PPAR $\alpha$ target genes since the PPAR-specific binding sequence (PPRE) has been detected in the promoter region of these genes. Administration of a PPAR a ligand will lead to the increased expression of such genes, which in turn will affect metabolism. This regulation is known as the PPAR $\alpha$ signaling pathway. The increased ACO activity and mRNA, as well as FABP mRNA, expression in H4IIEC3 cells treated with bitter gourd EA extract observed in this study indicate that bitter gourd EA extract may upregulate target genes of PPAR $\alpha$ in this cell line. As chimeric receptors were used in our transactivation assay, the results observed in H4IIEC 3 cells demonstrate that bitter gourd EA extract works on natural PPAR $\alpha$ and triggers the signaling pathway. It can thus be speculated that eating an appropriate amount of bitter gourd might have health benefits such as hypolipidemic effects through the PPAR $\alpha$ signaling pathway. It was reported that feeding a diet containing 0.5 or $1 \%$ freeze-dried bitter gourd powder significantly reduced liver triglycerides and cholesterol concentrations in rats [17]. We are currently conducting an in vivo animal experiment, and the results show that feeding bitter gourd EA extract upregulates the expression of some PPAR $\alpha$ target genes.

The most noteworthy health benefit of bitter gourd is the hypoglycemic potential demonstrated in normal [42] and diabetic $[2,6,34,37,39]$ rats as well as in human 
subjects with type II diabetes mellitus [23]. Using a rat model with high-fat-diet-induced obesity and hyperglycemia, it was [6] found that bitter gourd significantly reduced fasting plasma concentrations of glucose and insulin, and visceral fat pad weight, and improved oral glucose tolerance. The mechanism for the hypoglycemic effect of bitter gourd is still unknown, although it has been shown to inhibit glucose absorption [27], promote hepatic glucose utilization [37], possess an insulin-like polypeptide [20], and even to increase the insulin-positive cell number in the pancreas [1]. Excitingly, we observed that the bitter gourd EA extract could also activate PPAR $\gamma$, and the fold of activation was comparable to that of $0.5 \mu M \mathrm{BRL}-49653$. It is well known that the antidiabetic drug, thiazolidinedione, is a PPAR $\gamma$ ligand. It would be of great value to identify the compound responsible for PPAR $\gamma$ activation and test its antidiabetic potential.

Numerous biologically active components have been identified in bitter gourd. For example, seed extracts contain MAP-30, an anti-HIV and antitumor protein [24], momorcharins [32] and momordins [21], which inactivate ribosomes, and momordin Ic [25] and oleanolic acid glycoside [26], both of which can alter gastrointestinal transit time and blood glucose. In an attempt to search for the chemical constituent responsible for the hypoglycemic effect, a series of triterpene glycosides and oleanane-type triterpene saponins have been identified from Japanese bitter gourd fresh fruit, yet their biological effects have not been reported [30].

The lipid of bitter gourd seeds contains more than $50 \%$ of a conjugated linolenic acid (CLN), $\alpha$-eleostearic acid [9 cis (c), 11 trans $(t), 13 t$-18:3] [10, 40]. A small but distinct amount of a different CLN, $9 t, 11 t, 13 c-18: 3$ [40], was also found in the flesh of bitter gourd. As CLN has structural similarity with known PPAR activators, such as CLA, it can be speculated to be 1 of the chemical constituents that contribute to PPAR activation in bitter gourd. On the other hand, regardless of the big difference in the CLN con- tent between the seed and flesh of bitter melon, we observed no such big difference in folds of activation between seed and flesh extracts. Moreover, maximal folds of activation toward PPAR by common or uncommon fatty acids are generally much lower than those of drugs used as positive controls (Wy-14643 for PPAR $\alpha$ and BRL-49653 for PPAR $\gamma$ ) in the transactivation assay. Hence, bitter gourd may still contain chemical constituent(s) other than CLN that contribute to the high PPAR activation seen in this study.

In spite of its bitter taste that is unacceptable to some individuals, bitter gourd is a very common vegetable which has been consumed in oriental societies for hundreds of years. Data reported in this study indicate that this food material contains activators for both PPA$\mathrm{R} \alpha$ and PPAR $\gamma$. Irrespective of the fact that the molecular species responsible for PPAR $\alpha$ and PPAR $\gamma$ activation are still unknown, these data provide an evidence base indicating that it is worth designing clinical trials to test the potential health benefits of bitter gourd as part of the daily diet for improving hyperglycemic and hyperlipidemic conditions.

In conclusion, we used a transactivation assay to demonstrate that the EA extract of bitter gourd activated PPA$\mathrm{R} \alpha$ and PPAR $\gamma$ to an extent comparable to $\mathrm{Wy}-14643$ and BRL-49653, respectively. In H4IIEC 3 cells, the bitter gourd EA extract increased ACO activity and the expressions of ACO and FABP mRNA, indicating that it can also act on a natural PPAR $\alpha$ signaling pathway. It is worth further investigating the use of this common oriental vegetable to attain PPAR $\alpha$ - and PPAR $\gamma$-mediated health benefits, such as improving hyperlipidemic and hyperglycemic conditions.

\section{Acknowledgments}

This study was financially supported by a grant (NSC 89-2312B-002-013) from the National Science Council, Taiwan.

\section{References}

1 Ahmed I, Adeghate E, Sharma AK, Pallot DJ, Singh J. Effects of Momordica charantia fruit juice on islet morphology in the pancreas of the streptozotocin-diabetic rat. Diabetes Res Clin Pract 40:145-151:1998.

2 Akhtar MS, Athar MA, Yaqub M. Effect of Momordica charantia on blood glucose level of normal and alloxan-diabetic rabbits. Planta Med 42:205-212;1981.
3 Bar-Tana J. Peroxisome proliferator-activated receptor gamma (PPAR $\gamma$ ) activation and its consequences in humans. Toxicol Lett 120:9$19 ; 2001$.

4 Belury MA. Dietary conjugated linoleic acid in health: Physiological effects and mechanisms of action. Annu Rev Nutr 22:505-531;2002.
5 Chao PM, Chao CY, Lin FJ, Huang CJ. Oxidized frying oil up-regulates hepatic acyl-CoA oxidase and cytochrome $P_{450} 4 \mathrm{Al}$ genes in rats and activates PPAR $\alpha$. J Nutr 131:3166-3174; 2001.

6 Chen Q, Chan LLY, Li ETS. Bitter melon (MOmordica charantia) reduces adiposity, lower serum insulin and normalizes glucose tolerance in rats fed a high fat diet. $J$ Nutr 133:10881093;2003. 
7 Chinetti G, Fruchart JC, Staels B. Peroxisome proliferator-activated receptors (PPARs): Nuclear receptors at the crossroads between lipid metabolism and inflammation. Inflamm Res 49:497-505;2000.

8 Dallongeville $\mathrm{J}$, Bauge E, Tailleux A, Peters JM, Gonzalez FJ, Fruchart JC, Staels B. Peroxisome proliferator-activated receptor alpha is not-limiting for the lipoprotein-lowering action of fish oil. I Biol Chem 276:4634-4639; 2001.

9 Desvergne B, Wahli W. Peroxisome proliferator-activated receptors: Nuclear control of metabolism. Endocr Rev 20:649-688;1999.

10 Dhar P, Ghosh S, Bhattacharyya DK. Dietary effects of conjugated octadecatrienoic fatty acid (9 cis, 11 trans, 13 trans) levels on blood lipids and nonenzymatic in vitro lipid peroxidation in rats. Lipids 34:109-114;1999.

11 Ellinghaus $P$, Wolfrum $C$, Assmann $G$, Spener $F$, Seedorf U. Phytanic acid activates the peroxisome proliferator-activated receptor $a$ (PPARo) in sterol carrier protein 2-/ sterol carrier protein $\mathrm{x}$-deficient mice. J Biol Chem 274 2766-2772;1999

12 Heim M, Johnson I, Boess F, Bendik I, Weber P, Hunziker W, Fluhmann B. Phytanic acid, a natural peroxisome proliferator-activated receptor (PPAR) agonist, regulates glucose metabolism in rat primary hepatocytes. FASEB J 16:718-720;2002.

13 Henke BR, Blanchard SG, Brackeen MF, Brown KK, Cobb JE, Collins JL, Harrington WW, Hashim MA, Hull-Ryde EA, Kaldor I, Kliewer SA, Lake DH, Leesnitzer LM, Lehmann JM, Lenhard JM, Orband-Miller LA, Miller JF, Mook RA, Noble SA, Oliver W, Parks DJ, Plunket KD, Szewczyk JR, Willson TM. N-(2-benzoylphenyl)- $L$-tyrosine PPAR $\gamma$ agonists. 1. Discovery of a novel series of potent antihyperglycemic and antihyperlipidemic agents. J Med Chem 41:5020-5036:1998.

14 Higashino H, Suzuki A, Tanaka Y, Pootakham K. Hypoglycemic effects of Siamese Momordica charantia and Phyllanthus urinaria extracts in streptozotocin-induced diabetic rats. Nippon Yakurigaku Zasshi 100:415-421;1992.

15 Huang CJ, Feltkamp D, Nilsson S, Gustafsson JA. Synergistic activation of RLD 1 by agents triggering PKA and PKC dependent signalling. Biochem Biophys Res Commun 243:657-663; 1998.

16 Huang $\mathrm{CJ}, \mathrm{Wu} \mathrm{MC}$. Differential effects of foods traditionally regarded as 'heating' and 'cooling' on prostaglandin $\mathrm{E}_{2}$ production by a macrophage cell line. J Biomed Sci 9:596-606; 2002.

17 Jayasooriya AP, Sakono M, Yukizaki C, Kawano M. Yamamoto K. Fukuda N. Effects of Momordica charantia powder on serum glucose levels and various lipid parameters in rats fed with cholesterol-free and cholesterol-enriched diets. J Ethnopharmacol 72:331-336; 2000
18 Karunanayake EH, Welihinda J, Sirimanne SR, Sinnadorai G. Oral hypoglycemic activity of some medicinal plants of Sri Lanka. J Ethnopharmacol 11:223-231;1984.

19 Kersten S, Desvergne B, Wahli W. Roles of PPARs in health and disease. Nature 405:421424;2000.

20 Khanna P, Jain SC, Panagariya A, Dixit VP. Hypoglycemic activity of polypeptide-P from a plant source. J Nat Prod 44:648-655;1981.

21 Kimura $Y$, Minami Y, Tokuda T, Nakajima S, Takagi S, Funatsu G. Primary structures of $\mathrm{N}$ linked oligosaccharides of momordin-a, a ribosome-inactivating protein from Momordica charantia seeds. Agric Biol Chem 55:20312036;1991.

22 Kohno H, Suzuki R, Noguchi R, Hosokawa M, Miyashita K, Tanaka T. Dietary conjugated linolenic acid inhibits azoxymethane-induced colonic aberrant crypt foci in rats. Jpn J Cancer Res 93:133-142;2002.

23 Leatherdale BA, Panesar RK, Singh G, Atkins TW, Bailey CI, Bignell AHC. Improvement in glucose tolerance due to Momordica charantia (Karela). Br Med J 282:1823-1824;1981.

24 Lee-Huang S, Huang PL, Chen HC, Bourinbaiar A, Huang HI, Kuang HF. Anti-HIV and anti-tumor activities of recombinant MAP30 from bitter melon. Gene 161:151-156;1995.

$25 \mathrm{Li} \mathrm{Y}$, Matsuda H, Yamahara J, Yoshikawa M. Acceleration of gastrointestinal transit by momordin Ic in mice: Possible involvement of 5hydroxytryptamine, 5-HT(2) receptors and prostaglandins. Eur J Pharmacol 392:71-77; 2000.

26 Matsuda H, Li Y, Murakami T, Matsumura N, Yamahara J, Yoshikawa M. Antidiabetic principles of natural medicines. III. Structure-related inhibitory activity and action mode of oleanolic acid glycosides on hypoglycemic activity. Chem Pharm Bull 46:1399-1403;1998.

27 Meir P, Yaniv Z. An in vitro study on the effects of Momordica charantia on glucose uptake and glucose metabolism in rats. Planta Med 51:12-16:1985.

28 Miura T, Itoh C, Iwamoto N, Kato M, Kawai M, Park SR, Suzuki I. Hypoglycemic activity of the fruit of the Momordica charantia in type 2 diabetic mice. J Nutr Sci Vitaminol 47:340_ 344;2001.

29 MoyarCamarena SY, Vanden Heuvel JP, Blanchard SG, Leesnitzer LA, Belury MA. Conjugated linoleic acid is a potent naturally occurring ligand and activator of PPARQ. J Lipid Res 40:1426-1433:1999.

30 Murakami T, Emoto A, Matsuda H, Yoshikawa M. Medicinal foodstuffs. XXI. Structures of new cucurbitane-type triterpene glycosides, goyaglycosides-a, -b, -c, - $-\mathrm{d},-\mathrm{e},-\mathrm{f},-\mathrm{g}$, and $-\mathrm{h}$, and new oleanane-type triterpene saponins, goyasaponins I, II, and III, from the fresh fruit of Japanese Momordica charantia L. Chem Pharm Bull 49:54-63;2001.

31 Peters JM, Hennuyer N, Staels B, Fruchart JC, Fievet C, Gonzalez FJ, Auwerx J. Alterations in lipoprotein metabolism in peroxisome proliferator-activated receptor $a$-deficient mice. J Biol Chem 272:27307-27312;1997.
32 Pu Z, Lu BY, Liu WY, Jin SW. Characterization of enzymatic mechanism of gamma-momorcharin, a novel ribosome-inactivating protein with lower molecular weight of 11,500 purified from the seeds of bitter gourd $(\mathrm{MO}$ mordica charantia). Biochem Biophys Res Commun 229:287-294:1996.

33 Rosen ED, Spiegelman BM. PPAR $\gamma$ : A nuclear regulator of metabolism, differentiation, and cell growth. I Biol Chem 276:37731-37734; 2001.

34 Sarkar S, Pranava M, Marita R. Demonstration of the hypoglycemic action of Momordica charantia in a validated animal model of diabetes. Pharmacol Res 33:1-4;1996.

35 Schluter A, Barbera MJ, Iglesias R, Giralt M, Villarroya F. Phytanic acid, a novel activator of uncoupling protein- 1 gene transcription and brown adipocyte differentiation. Biochem $\mathbf{J}$ 362:61-69;2002.

36 Schoonjans K, Staels B, Auwerx J. Role of the peroxisome proliferator-activated receptor (PPAR) in mediating the effects of fibrates and fatty acids on gene expression. J Lipid Res 37 : 907-925;1996

37 Shibib BA, Khan LA, Rahman R. Hypoglycemic activity of Coccinia indica and Momordica charantia in diabetic rats: Depression of the hepatic gluconeogenic enzymes glucose-6phosphatase and fructose-1,6-bisphosphatase and elevation of both liver and red-cell shunt enzyme glucose-6-phosphate dehydrogenase. Biochem J 292:267-270;1993.

38 Small GM, Burdett K, Connock MJ. A sensitive spectrophotometric assay for peroxisomal acyl-CoA oxidase. Biochem J 227:205-210; 1985.

39 Srivastava $Y$, Venkatakrishna-Bhatt H, Verma Y, Venkaiah K, Raval BH. Antidiabetic and adaptogenic properties of Momordica charantia extract: An experimental and clinical evaluation. Phytother Res 7:285-289;1993.

40 Suzuki R, Arato S, Noguchi R, Miyashita K, Tachikawa $O$. Occurrence of conjugated linolenic acid in flesh and seed of bitter gourd. $J$ Oleo Sci 50:753-758;2001.

41 Torra IP, Chinetti G, Duval C, Fruchart JC, Staels B. Peroxisome proliferator-activated receptors: From transcriptional control to clinical practice. Curr Opin Lipidol 12:245-254; 2001

42. Welihinda J, Karunanayake EH. Extra pancreatic effects of Momordica charantia in rats. J Ethnopharmacol 17:247-255;1986.

43 Willson TM, Lambert MH, Kliewer SA. Peroxisome proliferator-activated receptor $\gamma$ and metabolic disease. Annu Rev Biochem 70:341$367 ; 2001$.

44 Wu MC, Huang CJ. Inhibition of prostaglan$\operatorname{din} E_{2}$ production of a macrophage cell line by some phytochemicals. Food Sci Agric Chem 3: $59-71 ; 2001$ 